\title{
Avaliação e caracterização de biofilme comestível de carboximetilcelulose contendo nanopartículas de quitosana e Cúrcuma longa
}

\author{
Evaluation and characterization of edible \\ carboxymethylcellulose biofilm containing \\ chitosan nanoparticles and turmeric
}

Vanessa Souza Santos ${ }^{1}$, Vanessa Solfa dos Santos ${ }^{1}$, Renan da Silva Fernandes ${ }^{1}$, Carlos Roberto Ferreira Júnior ${ }^{1}$, Fauze Ahmad Aouada ${ }^{1}$, Juliana H. Pinê Américo-Pinheiro ${ }^{2}$, Márcia Regina de Moura ${ }^{1}$

\footnotetext{
${ }^{1}$ Grupo de Compósitos e Nanocompósitos Híbridos (GCNH), Av. Brasil, 56, Centro, CEP: 15385-000, Ilha Solteira, São Paulo, Brasil.

${ }^{2}$ Universidade Brasil (UNIVBRASIL), Rua Carolina Fonseca, 584, CEP: 08230-030, São Paulo, São Paulo, Brasil.

e-mail: nessaisa@hotmail.com, solfavanessa@gmail.com,r.feernandes@yahoo.com.br,

carlosjunior.engmec@gmail.com, faouada@yahoo.com.br, americo.ju@gmail.com,marcia.aouada@unesp.br.
}

\begin{abstract}
RESUMO
A produção de biofilmes e revestimentos poliméricos a base de polímeros naturais, a fím de aplicá-los como embalagens de alimentos é alvo de constantes pesquisas, devido a necessidade de diminuir o volume de embalagens plásticas descartadas e otimizar as propriedades e validade dos alimentos. Dentre a imensa variedade de polímeros utilizados para esse fim, a carboximetilcelulose (CMC) destaca-se por apresentar características favoráveis para a formação de soluções filmogênicas, além de ser biodegradável e apresentar baixo custo. Visando potencializar as propriedades naturais desse polímero, pesquisadores tem utilizado aditivos que são incorporados a solução filmogênicas como nanopartículas de quitosana (NSQ) e Cúrcuma longa (C). A quitosana também é um polímero natural, amplamente utilizado em aplicações nos campos da farmacologia, tecnologia de biomateriais, biomedicina, agricultura e indústrias cosmética e alimentícia. A Cúrcuma longa derivada do açafrão, apresenta propriedade antioxidantes e antimicrobianas, que tem despertado bastante interesse, principalmente na indústria alimentícia, visando a substituição de antioxidantes sintéticos por esses materiais naturais. Neste trabalho, foram preparadas nanopartículas de quitosana por gelificação ionotrópica e incorporadas ao polímero (CMC), juntamente com a Cúrcuma longa, com o intuito de reforçar e potencializar as propriedades naturais desse polímero, para a preparação de biofilmes comestíveis. Após a preparação, caracterizá-los através de análises das propriedades mecânicas, permeabilidade ao vapor de água e ângulo de contato.
\end{abstract}

Palavras-chave: biofilmes comestíveis; polímeros naturais; nanopartículas de quitosana; cúrcuma longa

\section{ABSTRACT}

The production of biofilms and polymeric coatings based on natural polymers in order to apply them as food packaging is constantly being researched due to the need to decrease the volume of discarded plastic packaging and optimize the properties and validity of food. Among the immense variety of polymers used for this purpose, carboxymethylcellulose (CMC) has stood out for presenting favorable characteristics for the filmogenic solutions formation, besides being biodegradable and presenting low cost. Aiming to enhance the 
natural properties of this polymer, researchers have used additives that are incorporated into the filmogenic solution such as chitosan nanoparticles (NSQ) and turmeric. Chitosan is also a natural polymer, widely used in applications in the fields of pharmacology, biomaterials technology, biomedicine, agriculture and the cosmetics and food industries. Turmeric derived from saffron, has antioxidant and antimicrobial properties, which has aroused a lot of interest, especially in the food industry, aiming to replace synthetic antioxidants with these natural materials. In this work, chitosan nanoparticles were prepared by ionotropic gelation and incorporated into the polymer (CMC), along with turmeric, in order to reinforce and enhance the natural properties of this polymer for the preparation of edible biofilms. After preparation, they are characterized by analysis of mechanical properties, water vapor permeability and contact angle.

Keywords: edible biofilms, turmeric, carboxymethylcellulose, chitosan nanoparticles.

\section{INTRODUÇÃO}

Presente em praticamente todos os setores da economia, os biopolímeros movimentam um mercado que se desenvolve de maneira acelerada, principalmente pelo fato desses materiais terem se tornado uma alternativa ao uso de polímeros derivados do petróleo. Com propriedades biodegradáveis, os biopolímeros vem se destacando principalmente na indústria de alimentos, como matéria prima para o desenvolvimento de revestimentos e biofilmes comestíveis [1,2].

Esses biofilmes, tem sido alvo de intensos estudos nas últimas décadas, e sua aplicação vai muito além do que apenas formar uma barreira entre o meio interno e externo, elas são capazes de exercer funções específicas na preservação do alimento [3]. Funções essas, que resultam da presença de aditivos, como $a$ Cúrcuma longa $(\mathrm{C})$, que é uma planta monocotiledônea, comercialmente disponível como um pó extraído do rizoma da planta (açafrão- Cúrcuma longa), apresenta conteúdo de curcuminóides com $77 \%$ de curcumina, $17 \%$ de demetoxicurcumina e $6 \%$ de bis-demetoxicurcumina, compostos esses responsáveis pelas atividades antimicrobianas, antioxidante e anti-inflamatória dentre outros, que são agregadas a composição do biofilme final $[4,5]$. Materiais nanoestruturados, como nanopartículas de quitosana, também podem ser inseridos nas matrizes biopoliméricas como aditivos visando potencializar e/ou melhorar suas propriedades, uma vez que a matéria prima utilizada para a formação desses materiais (biopolímeros) ainda apresentam algumas limitações quando comparados as embalagens convencionais, como baixa propriedades físicas-químicas (mecânicas, térmicas e de barreira) [6,7].

Neste contexto, diversos biopolímeros como proteínas e polissacarídeos vem sendo estudados para o uso como matéria prima na produção desse tipo de material. Com grande destaque entre os pesquisadores, os polissacarídeos como amido, pectina, quitosana, alginato, celulose e seus derivados, tem ganhado notoriedade, por apresentarem excelentes propriedades mecânicas, ópticas e sensoriais, além de alto coeficiente de permeabilidade ao vapor de água, podendo ainda serem combinados entre si [8 - 10].

Entre os diversos materiais utilizados para a produção de filmes comestíveis e biodegradáveis supracitados, vamos destacar a carboximetilcelulose (CMC). Esse polissacarídeo, derivado da celulose destaca-se principalmente por suas características não tóxicas, biocompatibilidade, solubilidade em água, além de ser proveniente de fonte renováveis, o que o torna abundante e o faz ter baixo custo de obtenção [11]. Eles são capazes ainda de formar filmes transparentes, com alta manuseabilidade e matrizes contínuas com possibilidade de modificações em sua estrutura química, devido aos grupos hidroxilas presentes em sua estrutura conforme apresentado na Figura $1[12,13]$.

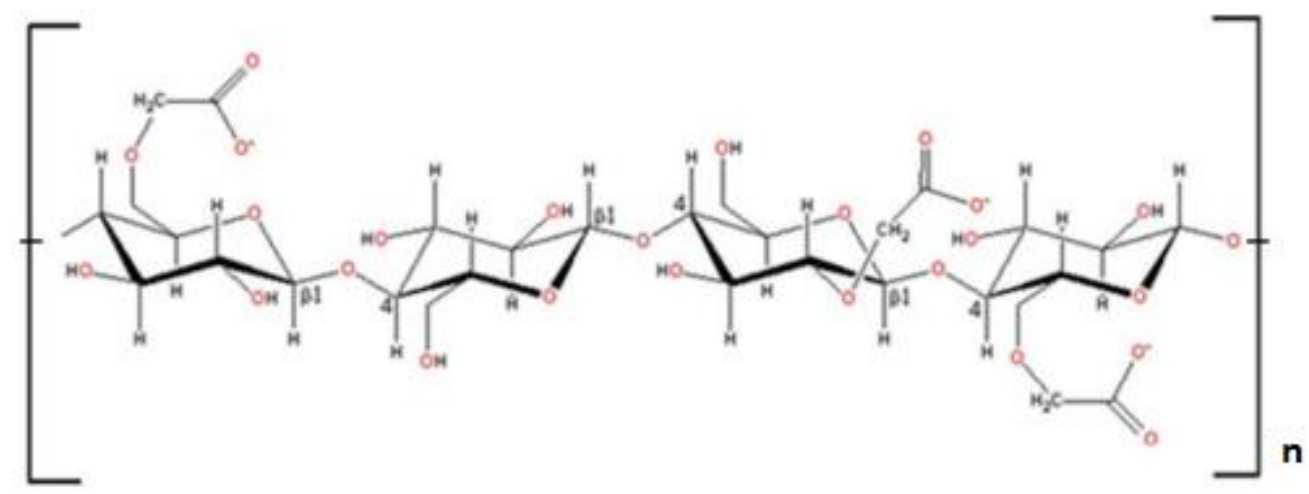

Figura 1: Estrutura química da Carboximetilcelulose [14] 
Tais modificações, permitem que esse polissacarídeo forme géis em baixas concentrações, o que favorece a formação de soluções filmogênicas para preparação dos biofilmes [15].

Considerando as propriedades satisfatórias do CMC e a necessidade de desenvolvimento de materiais alternativos e sustentáveis para a aplicação de embalagens na indústria de alimentos, o objetivo desse trabalho foi desenvolver e avaliar biofilmes comestíveis a base de carboximetilcelulose, com incorporação de Cúrcuma longa como agente antioxidante, reforçado com nanopartículas de quitosana.

\section{MATERIAIS E MÉTODOS}

\subsection{Material}

Todos os reagentes utilizados na preparação e nos procedimentos laboratoriais foram empregados sem purificação adicional. São eles: quitosana em pó da POLYMAR, Fortaleza-Brasil ( $\mathrm{MW}=71,3 \mathrm{kDa}$, grau de desacetilação 94\%), tripolifosfato de sódio (TPP) e ácido acético adquiridos da Sigma Aldrich Ltda (São Paulo, Brasil), carboximetilcelulose da Synth, lote: 123552 fabricante: Denver, extrato seco de Cúrcuma longa L.; fabricante: Pharma nostra, China, lote: CJH20160306 e o etanol do fabricante Synth, lote: 175010.

\subsubsection{Preparação das nanopartículas de quitosana}

As nanopartículas de quitosana (NSQ) foram preparadas por gelificação ionotrópica com a adição gota a gota de tripolifosfato (TPP), de acordo com a literatura [16], e o processo foi dividido em duas etapas. Na primeira etapa, preparou-se uma suspensão de quitosana $0,1 \%(\mathrm{~m} / \mathrm{v})$ sob agitação numa solução aquosa de ácido acético $0,2 \%(\mathrm{~m} / \mathrm{m})$ em relação à massa de quitosana a temperatura ambiente $\left(25^{\circ} \mathrm{C}\right)$ denominado de fase orgânica. Foi preparada também uma fase aquosa contendo $0,5 \%(\mathrm{~m} / \mathrm{v})$ de TPP dissolvida em água deionizada.

A segunda etapa consistiu na preparação das NSQ, para tal, adicionou-se $28 \mathrm{~mL}$ da solução de TPP em $70 \mathrm{~mL}$ da suspensão de quitosana sob agitação mecânica $(2500 \mathrm{rpm})$ e taxa de adição constante de $1 \mathrm{~mL} / \mathrm{min}$ por aproximadamente 30 min à temperatura ambiente $\left(25^{\circ} \mathrm{C}\right)$.

As nanopartículas são formadas imediatamente após a mistura de soluções de TPP e quitosana, conforme as ligações moleculares vão se formando entre os grupos fosfatos do TPP e amino da quitosana. Isso acontece devido a capacidade da quitosana de gelificar rapidamente no contato com poli ânions. $\mathrm{O}$ tamanho e a distribuição das nanopartículas de quitosana-TPP dependem amplamente da concentração, peso molecular e condições de mistura [17 - 19]

\subsubsection{Caracterização das nanopartículas}

\subsubsection{Tamanho médio e potencial Zeta}

A carga superficial (potencial zeta) e o tamanho médio das nanopartículas foram determinados em um aparelho Zetasizer Nano Series (Malvern Instruments Ltd. Malvern, Worcestershire, UK), utilizando o princípio da difração do raio laser. Para as análises foram utilizadas três gotas de cada suspensão de NSQ, diluídas em $3 \mathrm{~mL}$ de água deionizada, e as medidas foram realizadas em triplicata a $25^{\circ} \mathrm{C}$.

\subsubsection{Preparação dos filmes}

Foram preparados 4 filmes com soluções filmogênicas diferentes, através da técnica de "casting" (Figura 2) variando a composição de cada formulação, descritos a seguir:

Solução 1: $100 \mathrm{~mL}$ de solução aquosa de carboximetilcelulose 2\% (CMC);

Solução 2: $100 \mathrm{~mL}$ de solução aquosa de carboximetilcelulose $2 \%+20 \mathrm{~mL}$ de solução etanólica de Cúrcuma longa $0,1 \%,(\mathrm{CMC}+\mathrm{C})$;

Solução 3: $100 \mathrm{~mL}$ de solução aquosa de carboximetilcelulose $2 \%+80 \mathrm{~mL}$ de nanopartículas de quitosana (CMC + NSQ);

Solução 4: $100 \mathrm{~mL}$ de Carboximetilcelulose $2 \%+80 \mathrm{~mL}$ de nanopartículas de quitosana (descrita no item 4.2.1) + $20 \mathrm{~mL}$ de solução etanólica de Cúrcuma longa 0,1\% - (CMC + NSQ + C).

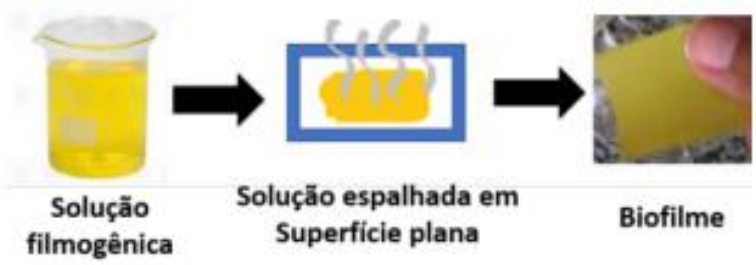


Figura 2: Esquema ilustrando a técnica "casting".

As soluções filmogênicas foram preparados conforme descrito abaixo e esquematizada pela Figura 3. Preparou-se uma solução de carboximetilcelulose $2 \%(\mathrm{~m} / \mathrm{v})$ e essa foi utilizada como base polimérica. Para tal, adicionou-se $80 \mathrm{~mL}$ de nanopartículas de quitosana numa taxa de $1 \mathrm{~mL} / \mathrm{min}$ em $100 \mathrm{~mL}$ de solução de carboximetilcelulose $2 \%(\mathrm{~m} / \mathrm{v})$ preparada inicialmente. A solução foi deixada sob agitação mecânica constante (800 a 1000 RPM) até o termino da adição das nanopartículas. Após esse período, à solução foi mantida sob agitação por mais 1 hora. Em seguida, adicionou-se a esta, uma solução etanólica contendo Curcuma longa a $0,1 \%(\mathrm{~m} / \mathrm{v})$ e deixada sob agitação constante por 30 minutos. Transcorridos esse período, a solução foi mantida em descanso por 10 minutos para subtração de possíveis bolhas e colocada para secar durantes $24 \mathrm{~h}$.

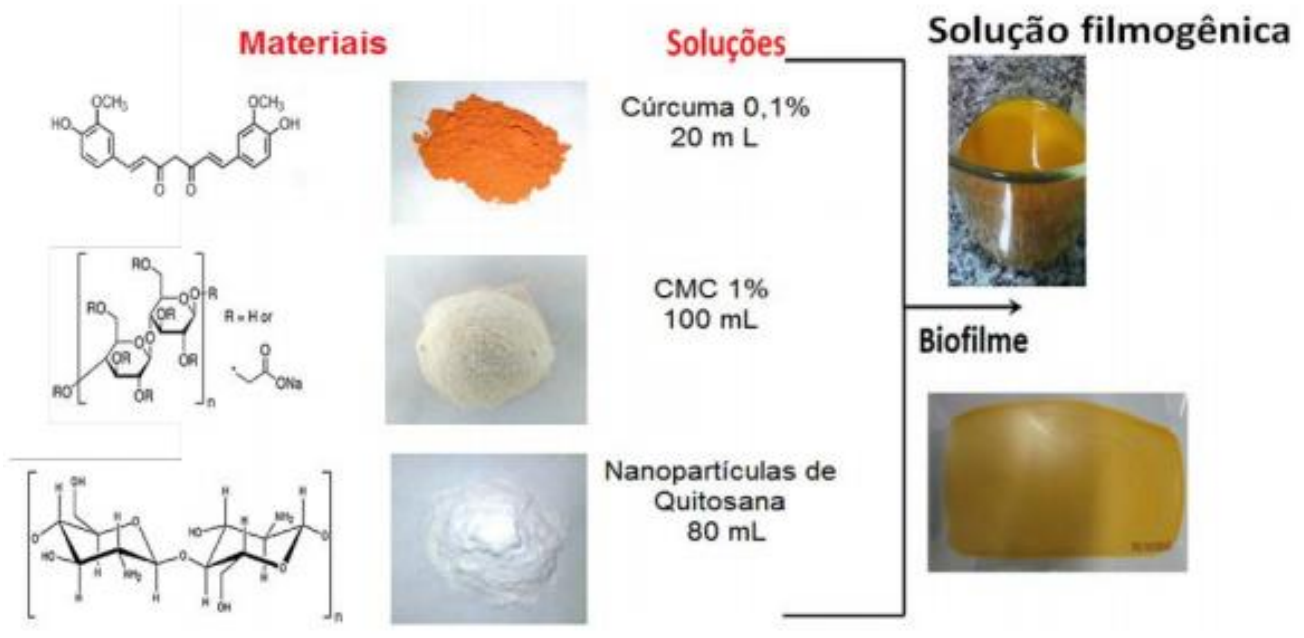

Figura 3: Esquema da metodologia adotada para produção da solução

\subsubsection{Caracterização dos filmes}

\subsubsection{Determinação da espessura dos filmes}

As espessuras dos filmes foram determinadas através de um micrômetro digital (Mitutoyo Manufacturing, Japan). As medidas foram realizadas através de 5 diferentes pontos na extensão do corpo de prova do filme utilizando- se a média. Os valores obtidos foram utilizados para calcular as propriedades mecânicas e os valores de permeabilidade de vapor de água.

\subsubsection{Permeabilidade ao vapor de água}

As análises de permeabilidade ao vapor de água, foram realizadas baseando-se no método modificado da ASTM E96-80, utilizado para determinar a umidade relativa $(\mathrm{RH})$ de filmes, descrito na literatura por MCHUGH et al. [20]. Para realização das análises, utilizou-se uma placa de teflon, e essas foram adicionados $6 \mathrm{ml}$ de água deionizada. Em seguida, os filmes cortados em formato de discos foram alocados sobre a base da placa, e fixados com parafuso na parte superior do suporte, conforme ilustra a Figura 4.

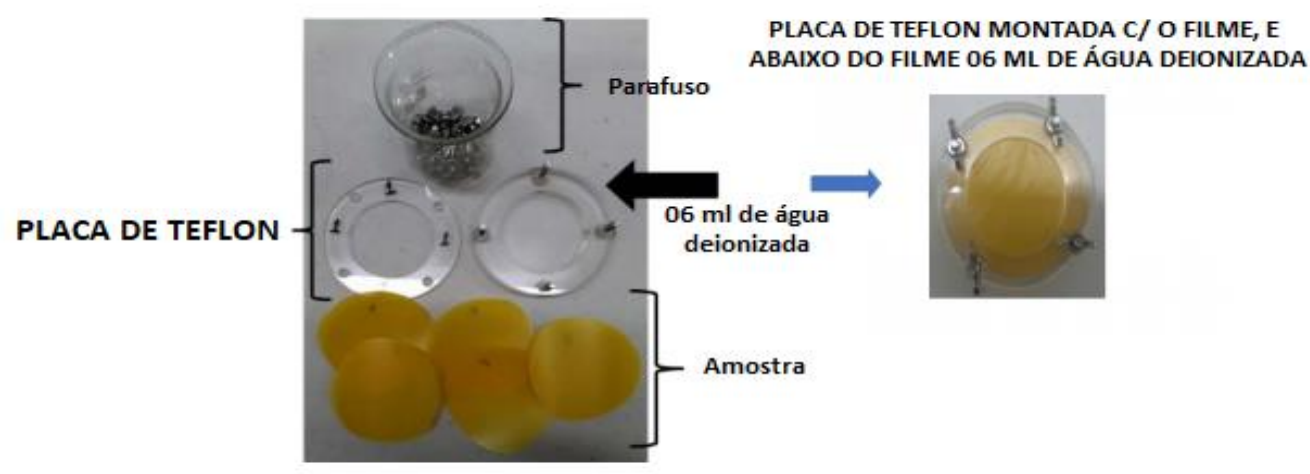


Figura 4: Placa de teflon e amostras utilizada na análise de WVP

As placas contendo as amostras foram acondicionadas em um ambiente de temperatura $\left(25^{\circ} \mathrm{C}\right) \mathrm{e}$ umidade $(50 \%)$ controlada (estufa), e essas foram submetidas a pesagens periódicas conforme descrito na literatura. Através dos valores das massas obtidos, foi possível determinar o WVP utilizando a Equação (1 2 e 3) de WVTR (Velocidade de transmissão de vapor de água).

$$
\begin{aligned}
& \begin{array}{l}
\text { Velocidade de transmissão de } \\
\text { vapor de água }(W V T R)
\end{array}=\frac{\text { perda de massa do filme }}{\text { área do filme }} \\
& W V T R=\frac{m w \cdot P \cdot D \cdot \ln \left[\left(p-p_{2}\right) /\left(p-p_{1}\right)\right]}{\text { R.T.z }} \\
& W V P=\frac{\text { WVRT }}{\left(p_{2}-p_{3}\right)} y
\end{aligned}
$$

Onde:

$\mathrm{mw}=$ massa molar da água $\left(18 \mathrm{~g} \mathrm{~mol}^{-1}\right)$;

$\mathrm{D}=$ difusividade do vapor de água pelo ar a $298 \mathrm{~K}\left(0,102 \mathrm{~m}^{2} \mathrm{~s}^{-1}\right)$;

$\mathrm{P}=$ pressão total $(1 \mathrm{~atm})$;

p1 = pressão de vapor a $298 \mathrm{~K}$;

$\mathrm{R}=$ constante dos gases $\left(82,1 \times 10^{-6} \mathrm{~m}^{3}\right.$ atm g $\mathrm{mol}^{-1} \mathrm{~K}^{-1}$;

$\mathrm{z}=$ altura média que o gás inerte atinge;

p2 = pressão parcial de vapor da parte inferior do filme;

p3 = pressão parcial de vapor da parte superior do filme;

$\mathrm{y}=$ espessura média dos filmes.

\subsubsection{3 Ângulo de contato}

O ângulo de contato foi medido em um goniômetro óptico (CAM 101, KSV Instruments, EUA) com uma câmera digital CCD KSV-5000. Para cada medida, padronizou-se $5 \mu \mathrm{L}$ de água destilada depositada na superfície do filme e 60 imagens foram registradas automaticamente no tempo experimental de 60 segundos. Os ângulos de contato foram determinados através de 5 repetições como descrito na ASTM D5725-99, sendo calculado pela média dos ângulos determinados.

\subsubsection{Propriedades mecânicas}

Para as análises de propriedades mecânicas utilizou -se a aplicação de tensão x deformação sob tração. Para tal, os filmes foram cortados em forma retangular nas dimensões de acordo com o método ASTM D882-9720 (15 mm de largura e $100 \mathrm{~mm}$ de comprimento) e acondicionados em um dissecador com umidade controlada e temperatura ambiente por $24 \mathrm{~h}$ antes dos testes.

Utilizou-se para a análise um Instron Universal Testing Machine (Modelo 3369, Instron Corp., Canton, Mass., U.S.A.), com velocidade de tracionamento de $50 \mathrm{~mm} / \mathrm{min}$. Para cada tipo de filme foram realizados pelo menos 5 ensaios e calculado a elongação $(\varepsilon)$, tensão $(\sigma)$ e módulo de elasticidade $(E)$ descritos pelas Equações $(4,5$ e 6$)$ respectivamente.

$$
\varepsilon=\ln \left(\frac{L}{L o}\right) \times 100
$$


Onde:

$\mathrm{L}=$ comprimentos de elongação do filme durante o experimento;

L0 = comprimento inicial do filme.

A força necessária de rompimento dos filmes foi determinada através da tensão $(\sigma)$, descrita pela Equação (5).

$$
\sigma=\frac{F}{S}
$$

Onde:

$\mathrm{F}=$ força de ruptura exercida

$\mathrm{S}=$ área seccional do filme.

O módulo de elasticidade (E) foi calculado através da tensão- deformação a partir da inclinação inicial da curva obtida conforme a Equação (6).

$$
(\sigma v s \varepsilon)
$$

\section{RESULTADOS}

\subsection{Caracterização das nanopartículas}

\subsubsection{Potencial Zeta e tamanho médio de nanopartículas (DLS)}

A estabilidade das nanopartículas foi determinada pelo potencial zeta e apresentou um valor de aproximadamente de $+30 \mathrm{mV}$. Tal resultado é devido a quitosana possuir uma estrutura cristalina rígida em virtude das ligações inter e intra moleculares com o hidrogênio. Por conta da repulsão de carga eletrostática entre as cadeias, as moléculas de quitosana em soluções aquosas, apresentam conformação estendida com cadeias mais flexíveis. Assim, quando a quitosana e a TPP foram misturadas entre si em solução de ácido acético, foram formados espontaneamente nano complexos compactos, com uma carga superficial positiva global e estáveis em solução [17]. Além de estáveis, as NSQ apresentaram um tamanho médio de $110 \mathrm{~nm}$, valor esse atribuído a concentração de TPP utilizada durante a síntese. Segundo RAMPINO et. al [21], em um estudo publicado em 2013, maiores concentrações de TPP na solução, contribuem para a formação de partículas com tamanho maiores, devido as ligações cruzadas predominantemente inter e intramoleculares da quitosana, que passam a ser associadas ao TPP [22].

\subsubsection{Caracterização dos filmes}

\subsubsection{Determinação da espessura dos filmes}

Os valores da espessura média e desvio padrão para as amostras dos diferentes filmes, estão apresentados na Tabela 1.

Tabela 1: Espessura média das amostras de filmes

\begin{tabular}{c|c}
\hline FILMES & ESPESSURA MÉDIA (MM) \\
\hline CMC & $0,33 \pm 0,003$ \\
\hline CMC+C & $0,48 \pm 0,003$ \\
\hline CMC+ NSQ & $0,43 \pm 0,003$ \\
\hline CMC+NSQ+C & $0,45 \pm 0,004$ \\
\hline
\end{tabular}

De acordo com os resultados é possível observar que todos os filmes contendo a matriz (CMC) com outro 
constituinte, apresentaram espessuras médias próximas e bem maior em comparação com o filme controle, contendo apenas a matriz. Tais resultados estão de acordo com a literatura que diz, que a espessura do filme está relacionada ao conteúdo sólido da solução filmogênicas. Portanto, quanto mais sólido participarem da solução, a tendência é que no final se obtenha filmes mais espessos [23].

\subsubsection{Permeabilidade ao vapor de água (WVP)}

Os resultados de WVP tem como objetivo investigar a propriedade de barreira dos filmes a vapores de água. Assim, foram realizadas as análises dos diferentes filmes, onde os valores encontram-se expressos na Figura 5 .

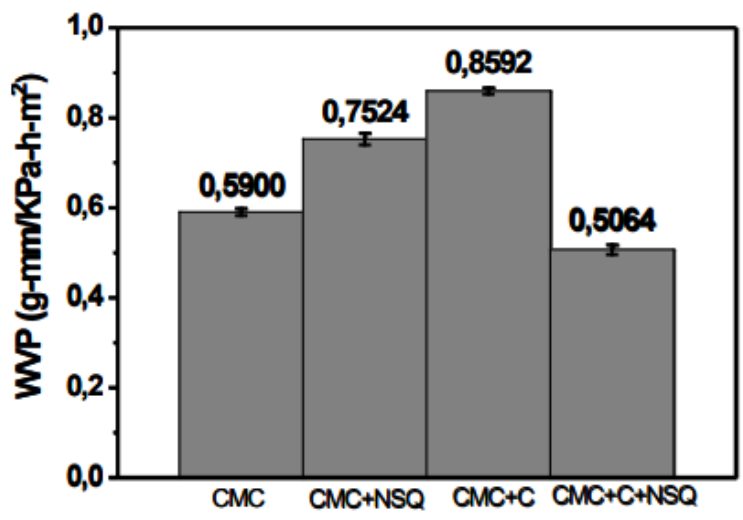

Figura 5: Valores médios de WVP e desvio padrão para os filmes de CMC puro, CMC+NSQ, CMC+C e $\mathrm{CMC}+\mathrm{NSQ}+\mathrm{C}$

Através dos resultados obtidos, é possível observar que, o filme controle (CMC) apresentou valor de permeabilidade menor que os filmes de CMC + NSQ e CMC + C. OS resultados podem ser atribuídos aos grupamentos hidrofílicos da cadeia polimérica da CMC, que podem estar interagindo entre si, causando uma aproximação das cadeias e impedindo a passagem dos vapores de água. Além disso, devido a alta densidade de grupamentos dessa natureza, esses podem estar livres (sem interações) e então interagir com o vapor de água, não permitindo que o mesmo permeie para o meio externo (Figura 6-A).

Para o filme de CMC + NSQ os valores de permeabilidade foram maiores do que os do filme controle, acredita-se que tal resultado está associado a hidrofilicidade das nanopartículas de quitosana. Possivelmente, esses grupamentos estão interagindo com os grupos hidrofílicos da cadeia de CMC, diminuindo o conteúdo de grupamentos livres (ponto de interação com o vapor) e facilitando desta maneira a passagem de água pela matriz polimérica (Figura 6-B). Segundo a literatura polímeros hidrofílicos, especialmente os altamente polares como a quitosana, podem, em função da umidade relativa em sua matriz, mudar significativamente sua permeabilidade a gases.

O filme de $\mathrm{CMC}+\mathrm{C}$, mesmo não sendo um composto com hidrofilicidade abundante, possui regiões hidrofílicas que possivelmente estão interagindo com os grupos da matriz polimérica, diminuindo possíveis pontos de interações matriz-vapor d'agua, contribuindo para a permeabilidade. $\mathrm{O}$ caráter apolar considerável da Cúrcuma longa também é um motivo fundamental que facilita a permeabilidade do vapor para o meio externo. Além disso, pode haver um fenômeno de repulsão entre as carbonilas da cadeia de Cúrcuma longa ou também com os grupamentos carboxílicos da CMC, deixando o material com espaços livres, o que favorece a passagem do vapor permeantes (Figura 6-C). Finalmente, ao analisar o filme completo o qual contém: CMC + NSQ + C, observa-se o menor valor de permeabilidade em relação as outras composições apresentadas. Neste caso as NSQ e Cúrcuma longa possivelmente estão se empacotando entre as cadeias de CMC preenchendo espaços vazios e dificultando a passagem de água, além do mais, essas substâncias provavelmente estão com grupamentos polares livres que certamente servirão como pontos de interação com os vapores permeantes resultando na baixa permeabilidade (Figura 6-D). Resultados apresentados por DESPOND et. al [24], indicam que para uma espessura constante e uma porosidade específica, a permeação torna-se sensível à concentração de água adsorvida pela película. 


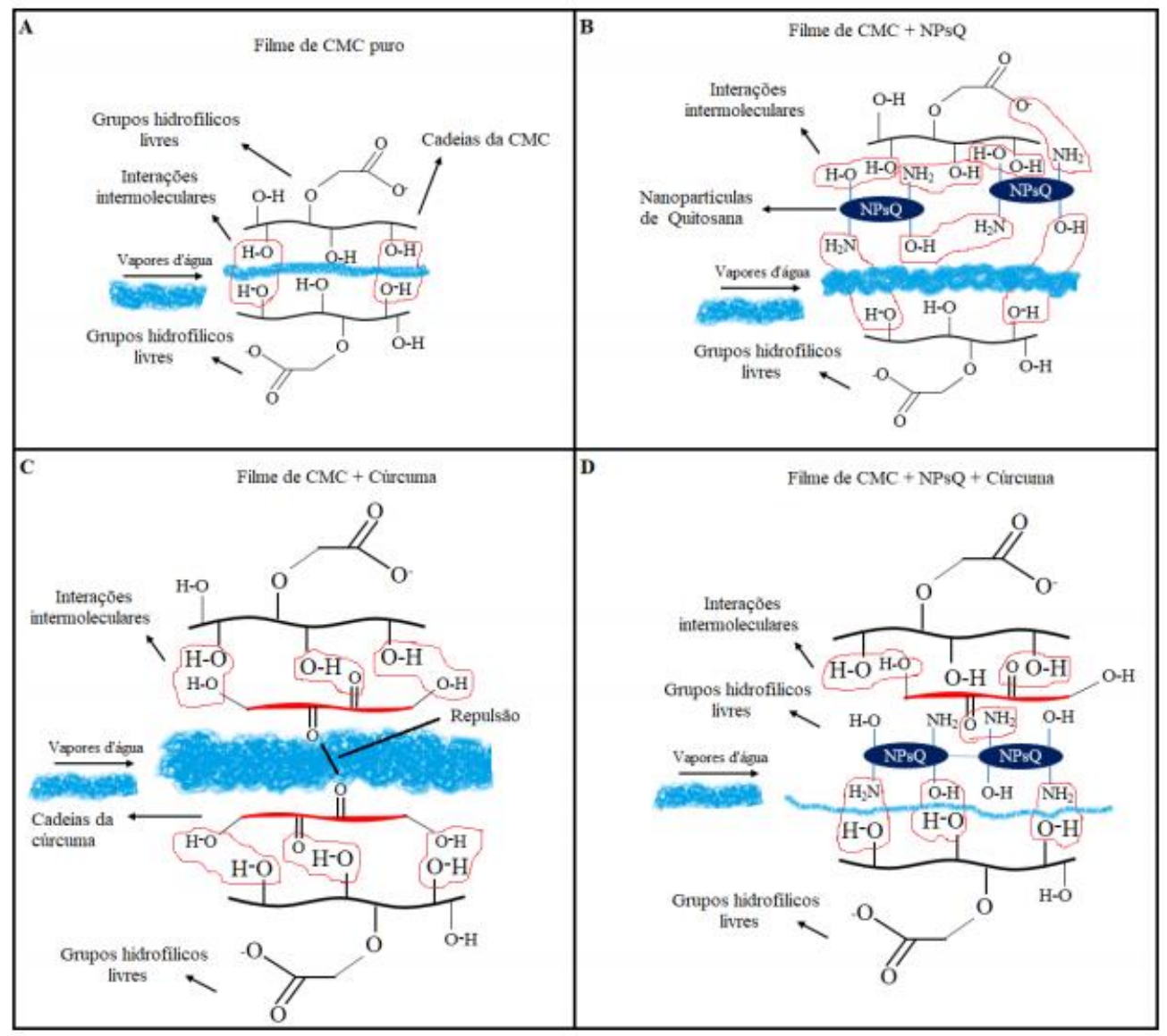

Figura 6: Modelo físico-químico hipotético proposto pelos autores para as análises de WVP.

\subsubsection{3 Ângulo de contato}

As medidas do ângulo de contato permitem avaliar o grau de molhabilidade (hidrofobicidade ou hidrofilicidade) dos filmes através da sua polaridade superficial [25]. Segundo a literatura, filmes com ângulo de contato com a água superior a $65^{\circ}$ são identificados como superfícies hidrofóbicas [26]. A Tabela 2 mostra os valores do ângulo de contato dos filmes, e permite investigar o efeito de incorporação das NPQS e Cúrcuma longa sobre a polaridade da superfície de cada um.

Tabela 2: Ângulo de Contato e Desvio Padrão dos filmes com água deionizada

\begin{tabular}{c|c}
\hline Amostra & Ângulo \\
\hline CMC & $42,02^{\circ} \pm 1,53$ \\
\hline CMC+C & $48,05^{\circ} \pm 1,03$ \\
\hline CMC + NSQ & $83,94^{\circ} \pm 6,64$ \\
\hline CMC + NSQ + C & $90,37^{\circ} \pm 6,09$ \\
\hline
\end{tabular}

De acordo com os resultados, os filmes contendo a matriz com Cúrcuma longa e/ou NSQ, tiveram um aumento no ângulo de contato em relação ao filme controle, contendo apenas o CMC. Esse aumento, indica que a incorporação tanto da Cúrcuma longa quanto das NSQ, tornou os filmes hidrofóbicos. Os resultados estão de acordo com o WVP, onde foi comprovado que, a presença das nanopartículas de quitosana e da 
cúrcuma na matriz favoreceram o preenchimento dos espaços vazios da cadeia polimérica de CMC, diminuindo assim a polaridade do filme, tornando-o menos permeável a moléculas de água e consequentemente, mais hidrofóbicos. Nos filmes contendo a cúrcuma, o aumento do ângulo de contato foi ainda mais evidente. Esse fato, ocorreu devido a Cúrcuma longa apresentar em sua estrutura química, partes hidrofóbicas e hidrofílicas, que lhe confere característica lipofílicas. Assim, mesmo em pequenas quantidades na composição dos filmes, ela contribui com a hidrofobicidade do filme com a água [27].

\subsubsection{Propriedades mecânicas}

As Figuras 7 e 8 ilustram os valores médios de elongação e tensão a ruptura dos diferentes filmes respectivamente. Pode-se observar que o filme contendo apenas CMC (controle) apresentou um baixo valor de elongação. Embora esse polímero seja largamente utilizado para produção de filmes comestíveis, ele não apresenta propriedade mecânicas satisfatórias, sendo geralmente preciso utilizar aditivos visando a melhoria dessas propriedades. Neste contexto, a adição de nanopartículas de quitosana e Cúrcuma longa mostrou que houve um aumento considerável nessa propriedade principalmente no filme completo contendo NSQ e Cúrcuma longa. Esse aumento provavelmente está relacionado a interação das nanopartículas de quitosana e da Cúrcuma longa a carboximetilcelulose. Essa interação preenche os espaços vazios na cadeia polimérica da CMC dando um efeito de reticulação extra ao filme incorporado [28].

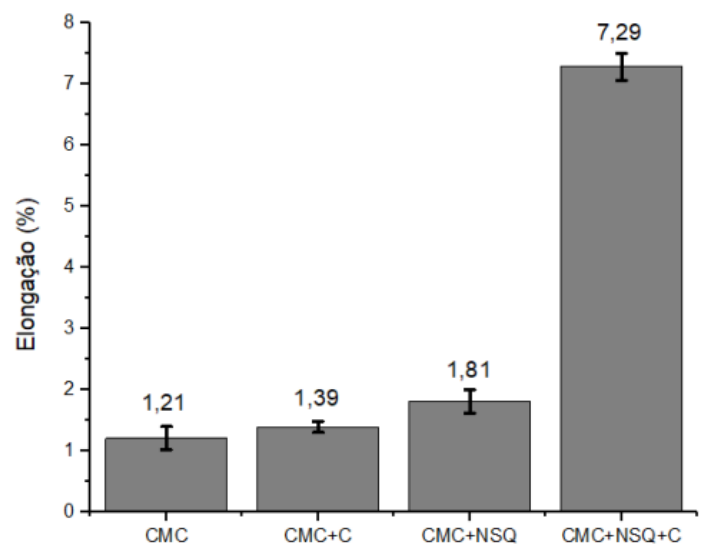

Figura 7: Valores médios de elongação e desvio padrão dos filmes

A rigidez do filme foi determinada através das análises da tensão, e são mostradas na Figura 8 . A tensão dos filmes assim como a elongação aumentaram com a presença das NSQ e/ou Cúrcuma longa, quando comparados ao filme de CMC puro. $\mathrm{O}$ aumento dessa propriedade, pode ser devido à interação entre o grupo -OH e outros compostos fenólicos presentes na Cúrcuma longa, com grupos $-\mathrm{NH}_{2}$ da quitosana [29]. O decréscimo no valor de tensão média do filme contendo $\mathrm{CMC}+\mathrm{NSQ}+\mathrm{C}$, comparado com o filme de $\mathrm{CMC}+\mathrm{NSQ}$, está relacionado com a insolubilidade da Cúrcuma longa que, promove na estrutura do filme uma menor interação com a matriz polimérica o que pode ter gerado uma faixa de separação de fases e, consequentemente, uma redução desta propriedades físico-mecânicas [30]. Em resultados publicados por LIU et al. [32], foram avaliados filmes de quitosana incorporados com curcumina, foi possível observar que houve um aumento da tensão em 2 vezes quando comparado com o filme sem a curcumina. Tais resultados, também foram observados por BITENCOURT et al. [33], que relatou um aumento da tensão nos filmes de gelatina com a adição de curcumina, provavelmente devido à interação entre peptídeos de gelatina e curcumina. A curcumina é uns dos principais componentes da Cúrcuma longa, porém assim como ela, outros curcuminóides compõem sua estrutura. Esses compostos estabelecem uma forte interação com a estrutura da quitosana, tornando o filme mais resistente, aumentando assim, a tensão.

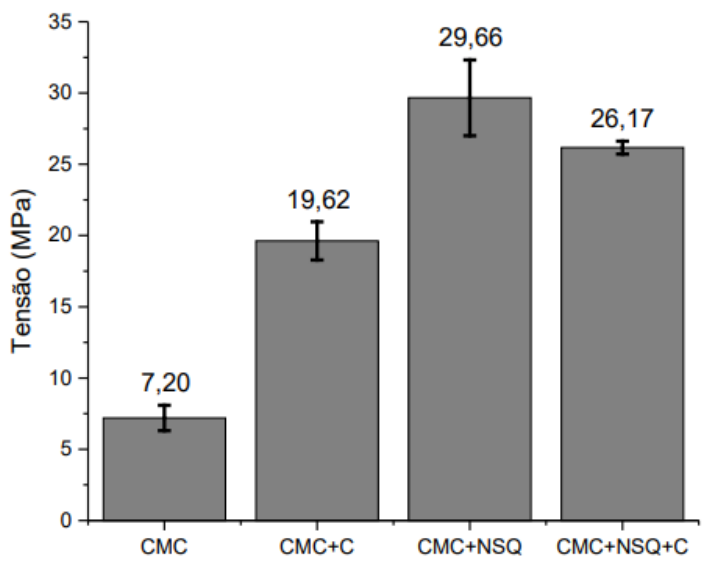


Figura 8: Valores médios de tensão e desvio padrão

Em função das características e propriedades apresentadas pelo filme, este tem grande potencial de aplicação como embalagens primárias em produtos cárneos [32]. Assim como em embalagens primárias para transporte de alimentos farináceos por exemplo o pão, tal afirmação baseia-se em estudos de SINGH et. al (2011) que descreveu que a cúrcuma apresentou potencial antimicrobiano contra o patógeno Aspergillus, que é encontrado principalmente em pães deteriorados [33]. Por outro lado, os autores afirmam que há possibilidade de aplicação inédita destes filmes na área da piscicultura, como revestimento de ração para peixes, a fim de aumentar o tempo de superfície da ração.

\section{CONCLUSÕES}

De acordo com os resultados obtidos neste trabalho, pode-se concluir que, as NSQ obtidas pelo método de gelificação ionotrópica, resultaram em nanopartículas satisfatórias com uma média de diâmetro de $110 \mathrm{~nm}$, apresentando boa estabilidade conforme demonstra os dados de potencial zeta que foram superiores a +30 $\mathrm{mV}$. Todas as formulações de filmes apresentaram características visuais satisfatórios para aplicação em embalagens como boa homogeneidade, continuidade e manuseabilidade. Os ensaios mecânicos apontaram um significativo aumento na elongação, confirmando que tanto as NSQ quanto a Cúrcuma longa estão favorecendo a elasticidade do filme, além de torná-lo mais rígido, características essas favoráveis para a utilização como embalagens comestíveis. Os filmes apresentaram ainda, boas propriedades de barreira, comprovadas pela análise de WVP, sendo o melhor, o filme completo contendo CMC, NSQ e Cúrcuma longa. Onde foi possível observar que, tais aditivos de fato contribuíram para a melhora das propriedades físicas, mecânicas e de barreiras, além de torná-lo mais hidrofóbico conforme mostram os resultados de ângulo de contato, mediante as interações desses compostos com a matriz polimérica, que ocasionam um empacotando entre as cadeias de CMC.

\section{AGRADECIMENTOS}

Os autores agradecem: FAPESP (Proc. 2013/07296-2 e Proc. 2019/06170-1), CAPES (Código de financiamento 001) e CNPq (PQ 312530/2018-8 e PQ 312414/2018-8).

\section{BIBLIOGRAFIA}

[1] MALATHI, A.N., SANTHOSH, K.S., NIDONI,U. Recent trends of biodegradable polymer: biodegradable films for food packaging and application of nanotechnology in biodegradable food packaging. Current Trends in Technology, v. 3, n. 2, pp 73, 2014.

[2] STEPHEN, A.M.; PHILLIPS, G.O.; WILlIAMS, P.A. Food Polysaccharides and their applications, 2nd ed., chapter. 1, 7 e 8, Florida, USA, CRC Press, 2006.

[3] LUCENA, C.A.A, COSTA, S.C., ELEAMEN. G.R.A., et al., Development of xylan and xylan/gelatin biofilms for production of biodegradable packages. Polímeros, 27(número especial), pp 35-41, 2017.

[4] GAVINDARAJ, P., KANDASUBRAMANIAN, B., KODAM, M.K. Molecular interations and antimicrobial activity of curcumim (Curcuma longa) loaded polyacrylonitrile films. Materials Chemistry and Physics, v. 147, pp. 934-941, 2014.

[5] SILVA, M.C. et al., Avaliação do método de obtenção de scaffolds quitosana/curcumina sobre a estrutura, morfologia e propriedades térmicas. Materia. v. 21, n.03, pp. 560-568, 2016.

[6] ANTONIOU, J. et al., Characterization of tara gum edible films incorporated with bulk chitosan and chitosan nanoparticles: a comparative study. Food Hydrocolloids, v. 44, pp. 309- 319, 2015.

[7] ESPITIA, P.J.P., DU, W.-X., AVENA-BUSTILLOS, R.J., el tal. "Edible films from pectin: physicalmechanical and antimicrobial properties - a review". Food Hydrocolloid, v. 35, pp 287, 2014 a.

[8] GALlO, J. A. Q., DEBEAUFORT, F., CALLEGARIN, F., et al.,"Lipidic hydrophobic, physical state and distribution effects on the properties of emulsion-based films". Journal Membrane Science, v. 180, n. 1, pp. 37- 46, 2000.

[9] CUQ, B., GONTARD, N., GUILBERT, S., "Edible film and coating as active layers", In: ROONEY, M. L. (eds.) Active food packaging. London: Blackie Academic \& Professional, pp. 111-142, 1995. 
[10] AKHOURI, F.M., et al. "Filmes e coberturas comestíveis compostas à base de amidos nativos e gelatina na conservação e aceitação sensorial de uvas Crimson”. Ciência e Tecnologia de Alimentos, v. 27, n. 2, pp. 369-375, Jun.2007.

[11] SHALABY, S.W, SHAH, K.R. "Chemical modifications of natural polymers and their technological relevance in Water Soluble Polymers: Synthesis, Solution Properties, and Applications". ACS Symposium Series, American Chemical Society, pp. 467, 1991.

[12] WILSON, P.F. NETO. et al. "Preparation and characterization of nanocomposites of the carboxymethyl celulose reinforced with celulose nanocrystals", Macromolecular Symposia, v. 319, pp. 93-98, 2012.

[13] KAISTNER, U., HOFFMANN, H., DONGES, R., et. al., "Structure and solution properties of sodium carboxymethyl cellulose, Colloids Surfaces “, Physicochemitry, v. 123-124, pp. 307-328, 1996.

[14] KAISTNER, U., HOFFMANN, H., DONGES, R., et al., Structure and solution properties of sodium carboxymethyl cellulose, Colloids Surfaces A: Physicochem, v. 123-124, pp. 307-328, 1996.

[15] CARASCHI, J.C., CAMAPANA-FILHO, S.P. "Influência do grau de substituição e da distribuição de substituintes sobre as propriedades de equilíbrio de carboximetilcelulose em solução aquosa. Polímeros",Ciência e Tecnologia, v. 19, n. 2, 1999.

[16] CALVO, P., REMUNAN-LOPEZ, C., VILA-JATO, J., el. al., "Novel hydrophilic chitosanpolyethylene oxide nanoparticles as protein carriers". Journal of applied polymer science., v. 63 pp.125, 1997.

[17] GAN, Q., WANG, T., COCHRANE, C., et, al., "Modulation of surface charge, particle size and morphological properties of chitosan-TPP nanoparticles intended for gene delivery", Colloids and Surfaces B: Biointerfaces, v. 44, n. 2-3, pp. 65-73, 2005.

[18] DE CAMPOS, A.M., SANCHEZ, A., ALONSO, M.J., "Chitosan nanoparticles: a new vehicle for the improvement of the delivery of drugs to the ocular surface. Application to cyclosporin”. International Journal of Pharmaceutics, v. 224, pp. 159-168, 2001.

[19] XU, Y.M., DU Y.M. "Effect of molecular structure of chitosan on protein delivery properties of chitosan nanoparticles", International Journal of Pharmaceutics, v. 250, pp. 215-226, 2003.

[20] MCHUGH, T.H., AVENA-BUSTILlOS, R., KROCHTA, J.M. "Hydrophilic edible films: modifield procedure for water vapor permeability and explanation of thickness effects". Journal of Food Science, v. 58, pp. 899, 1993.

[21] RAMPINO, A., BORGOGNA, M., BLASI, P., et al., "Chitosan nanoparticles: Preparation, size evolution and stability”, International Journal of Pharmaceutics, v. 455, n. 1-2, pp. 219-228, 2003.

[22] MORRIS, G.A., CASTILE, J., SMITH, A., et. al., "The effect of prolonged storage at different temperatures on the particle size distribution of tripolyphosphate (TPP)-chitosan nanoparticles". Carbohydrate. Polymer, v. 84, pp. 1430-1434, 2011.

[23] MOHAMMADI, H., KAMKAR, A., MISAGHI, A."Nanocomposite films based on CMC, okra mucilage and $\mathrm{ZnO}$ nanoparticles: Physico mechanical and antibacterial properties". Carbohydrate Polymers, v 181, pp. 351-357, 2018.

[24] DESPOND, S., ESPUCHE, E., DOMARD, A. "Water Sorption and Permeation in Chitosan Films: Relation between Gas Permeability and Relative Humidity. "Journal of Polymer Science.: Part B: Polymer Physics, v. 39, pp. 3114-3127, 2001.

[25] SU, J.F., HUANG, Z., YUAN, X.Y. et al., "Structure and properties of carboxymethyl celulose/soy protein isolate blend edible films crosslinked by Maillard reactions". Carbohydrate. Polymer, v. 79, pp.145, 2010.

[26] VOGLER, E.A. "Structure and reactivity of water at biomaterial surfaces". Adv. Colloid Interface Science., 74, pp. 69, 1998.

[27] PÉREZ-MATEOS, M., MONTERO, P., GÓMEZ-GUILLÉN, M.C. "Formulation and stability of biodegradable films made from cod gelatin and sunflower oil blends". Food Hydrocolloid, v.23, n. 1, pp. 53$61,2009$.

[28] KALAYCIOĞLU, Z., TORLAK, E., AKIN-EVINGÜR, ÖZEN, F.I., et al., “Antimicrobial and physical properties of chitosan films incorporated with turmeric extract", International Journal of Biological Macromolecules, v.101, pp. 882-888, 2017.

[29] ROHR, T.G. "Estudo Reológico da mistura carboximetilcelulose/amido e sua utilização como veículo de inoculação bacteriano”. Dissertação de M. Sc., Universidade Federal Rural do Rio de Janeiro, RJ, Brasil, 2007.

[30] LIU, Y., CAI, Y., JIANG, X., et al., "Molecular interactions, characterization and antimicrobial activity 
of curcumin-chitosan blend films". Food Hydrocolloids, v. 52, pp. 564-572, 2016.

[31] BITENCOURT, C.M., FÁVARO-TRINDADE, C.S., SOBRAL, P.J.A. et. al. "Gelatin-based films additivated with curcuma ethanol extract: antioxidant activity and physical properties of films". Food Hydrocolloids, v.40, pp. 145-152, 2014.

[32] CHOI, I., LEE, S.E., CHANG, Y., et al., Effect of oxidized phenolic compounds on cross-linking and properties of biodegradable active packaging film composed of turmeric and gelatin, LWT, v.93, pp. 427433, 2018.

[33] SINGH, S., SANKAR, B., RAJESH, S., et al., Chemical Composition of Turmeric Oil (Curcuma longa L.cv. Roma) and its Antimicrobial Activity against Eye Infecting Pathogens. Journal of Essential Oil Research, v. 23, n. 6, pp. 11-18, 2011.

\section{ORCID}

Vanessa Souza Santos

não informado

Vanessa Solfa dos Santos

https://orcid.org/0000-0002-1782-0107

Renan da Silva Fernandez

https://orcid.org/0000-0002-2059-4016

Carlos Roberto Ferreira Júnior

não informado

Fauze Ahmad Aouada

https://orcid.org/0000-0002-6870-6961

Juliana H. Pinê Américo-Pinheiro

https://orcid.org/0000-0001-6252-828X

Márcia Regina de Moura

https://orcid.org/0000-0002-2534-5553 